Article

\title{
Research on the Combustion Characteristics and Kinetic Analysis of the Recycling Dust for a COREX Furnace
}

\author{
Haiyang Wang, Jianliang Zhang, Guangwei Wang *, Di Zhao, Jian Guo and Tengfei Song \\ School of Metallurgical and Ecological Engineering, University of Science and Technology Beijing, \\ Beijing 100083, China; 18811770953@163.com (H.W.); zhang.jianliang@hotmail.com (J.Z.); \\ 17801036074@163.com (D.Z.); 18612537348@163.com (J.G.); songtengfei1030@163.com (T.S.) \\ * Correspondence: wgw676@163.com; Tel.: +86-138-1118-5467 \\ Academic Editor: Enrico Sciubba \\ Received: 9 August 2016; Accepted: 22 January 2017; Published: 20 February 2017
}

\begin{abstract}
Thermogravimetric analysis of recycling dust (RD) from the melter gasifier of COREX, coke1 (C-1), coke2 (C-2) and coal char (CC) under 70\% oxygen atmosphere was carried out using thermal balance. The chemical composition and physical structure of the samples were investigated. The characteristic temperatures and comprehensive combustion characteristic indexes were calculated and kinetic parameters during the combustion process were calculated as well using a distributed activation energy model (DAEM). The results show that the carbon in the recycling dust originates from unconsumed CC and coke fines, and the average stacking height of carbon in RD is larger than that of C-1, C-2 and CC. The conversion curves of RD are different from those of C-1, C-2 and CC, and there are two peaks in the RD conversion rate curves. The combustion profiles of $\mathrm{RD}$ moves to a higher temperature zone with increasing heating rates. The average activation energies of their combustion process for RD, C-1, C-2 and CC range from $191.84 \mathrm{~kJ} / \mathrm{mol}$ to $128.31 \mathrm{~kJ} / \mathrm{mol}$. The activation energy for recycling dust increases as the fractional conversion increases, but the value for C-1, C-2 and CC decreases with increasing conversion, indicating different combustion mechanisms.
\end{abstract}

Keywords: COREX; recycling dust; combustion kinetic analysis; distributed activation energy model (DAEM)

\section{Introduction}

The COREX process, an alternative iron-making technology, is independent on coking coal to meet the environmental and source requirements, and it has been successfully applied in China, India, South Africa and South Korea [1,2]. Two COREX-3000 processes, the melting rate of which aims to reach approximate $150 \mathrm{t} / \mathrm{h}$, were introduced in 2007 and 2011 in China, respectively. However, for the sake of taking advantage of low iron costs, one of the COREX-3000 processes was entirely moved to Xinjiang, a large region with abundant sources of low rank coal and iron ore.

The COREX process can be studied according to the investigations by Wu et al. [3,4]. It consists of two reactors: the prereduction shaft furnace and the melter gasifier. The raw materials, i.e., lump ore, pellet, coke and fluxes, are continuously charged into the shaft furnace, while large amounts of coke and lump coal are charged into the melter gasifier. The reducing gas at about $1223 \mathrm{~K}$ is introduced through the bustle and moves in a countercurrent direction to the top of the shaft furnace. Hot DRI produced by the shaft furnace is discharged at the top of the melter gasifier, and oxygen, which reacts with the coke and coal char (CC) to generating reducing gas and heat, is blown through the tuyeres. The recycling dust of this process, which contains abundant carbon and metallic iron, is ignited by oxygen injected through the oxygen coal lance. The combustion of the recycling dust 
generates reducing gas and releases a large amount of heat, which is important for controlling the temperature of the dome, and must be maintained above $1223 \mathrm{~K}$ to guarantee the reduction reaction in the pre-reduction furnace. However, the temperature of the reducing gas in the dome cannot be higher than $1323 \mathrm{~K}$, otherwise, the coal ash would soften and bond the dust to block the generator gas nozzles.

Therefore, maintaining a stable temperature in the dome is of great importance, making studies on the combustion of the recycling dust interesting. Sun et al. [5] analyzed the impact of operation parameters on the temperature in the dome mainly by regression analysis. Liu et al. [6] investigated the pyrolysis process of lump coal in a COREX melter gasifier, however, combustion of the recycling dust was not reported in their work. Berger et al. [7] investigated the combustion of the recycling dust in front of the dust burner using different numerical approaches, and their results showed that the temperature in this region is about $1174 \mathrm{~K}$, which is lower than the practical data. Wu et al. [8] studied combustion reaction using three-dimensional steady-state model. It indicated that the carbon in the recycling dust was completely consumed, and the highest temperature in this region can be above $3000 \mathrm{~K}$. Du et al. [9] discussed the inherent characteristics of the recycling dust using experimental data, and the combustion reaction process was studied through a three-dimensional steady state mathematical model.

Combustion of coal and other carbonaceous materials, such as biomass, under enriched oxygen atmospheres has been investigated by several researchers. Liu et al. [10] investigated the co-combustion of biomass and bituminous coal under $100 \%$ and $80 \%$ oxygen atmospheres, and it was seen that the combustion performance of the blends was obviously improved by increasing the oxygen content. Gong et al. [11] studied the effect of $\mathrm{CeO}_{2}$ on combustion performance of acid-treated coal under an oxygen atmosphere, and it is more drastic compared with combustion under an air atmosphere. Nevertheless, work related to the combustion performance of the recycling dust under an enriched oxygen atmosphere and its kinetic analysis has never been reported.

The origin of carbon in the recycling dust (RD) was investigated by petrographic analysis in this work. Meanwhile, the micromorphology and microcrystalline structure of carbon in the recycling dust were studied using a scanning electron microscope (SEM) and X-ray diffraction (XRD) after acid treatment as well. The combustion characteristics of RD was analyzed by thermogravimetric analysis and the kinetic parameters were calculated using the distributed activation energy model (DAEM). It is expected that this research will be useful in understanding the combustion process of recycling dust and provided information required for design and operation of the dust burner.

\section{Experimental Procedure}

\subsection{Preparation of Samples}

The samples studied in this work were obtained from the reducing gas generation pipe of COREX-3000, an alternative process used for iron-making in China, when it is damping down. The dust was dried in a drying oven at $378 \mathrm{~K}$ for $8 \mathrm{~h}$. Because the combustion of carbon in the recycling dust is the major exothermic reaction, the characteristics and combustion process of the carbon must be investigated seriously. Excess $6 \mathrm{~N} \mathrm{HCl}$ was used to treat the recycling dust for eliminating the interference of inorganic matter [11,12]. Samples were treated until the mass fraction of ash remained lower than $5 \%$, suggesting that the influence of inorganic matter can be ignored. CC was prepared at $1473 \mathrm{~K}$ for $30 \mathrm{~min}$ under $\mathrm{N}_{2}$ atmosphere, and cokes were treated under the same conditions for comparison. The proximate and ultimate analysis of all samples, including recycling dust (RD), coke1 (C-1), coke2 (C-2) and CC, before and after acid treatment were analyzed according to GB212-2001 and GB476-2001. The results are shown in Table 1.

The microcrystalline structure of RD, C-1, C-2 and CC were measured by an Ultima IV X-ray diffraction analyzer (Rigaku Co., Ltd., Tokyo, Japan), while a Quanta 250 environmental SEM (FEI, Houston, TX, USA) was applied to obtain the micromorphology of the samples. As both coke and 
pulverized coal are used as fuel for melter gasifiers, the carbon in the recycling dust may originate from different regions according to researchers [13-17]. The origin of carbon was investigated by petrographic analysis using an OPTON-II polarizing microscope (Carl Zeiss AG, Oberkochen, Germany). The area ratio of different components including unconsumed coal and fine coke as well as oxide was determined by the microscopic analysis method.

Table 1. Proximate and ultimate analysis of samples before and after acid-washing treatment/wt $\%$.

\begin{tabular}{|c|c|c|c|c|c|c|c|c|c|}
\hline \multirow{2}{*}{ Treat } & \multirow{2}{*}{ Sample } & \multicolumn{4}{|c|}{ Proximate Analysis } & \multicolumn{4}{|c|}{ Ultimate Analysis } \\
\hline & & $\mathrm{FC}_{\mathrm{d}}{ }^{\mathrm{a}}$ & $\mathbf{A}_{\mathrm{d}}$ & $\mathrm{V}_{\mathrm{d}}$ & $C_{d}$ & $\mathbf{H}_{\mathbf{d}}$ & $\mathrm{O}_{\mathrm{d}}{ }^{\mathrm{a}}$ & $\mathbf{N}_{\mathrm{d}}$ & $S_{d}$ \\
\hline \multirow{4}{*}{ Before acid treatment } & RD-B & 27.18 & 68.22 & 4.60 & 28.50 & 0.07 & 2.73 & 0.19 & 0.29 \\
\hline & C-1-B & 83.31 & 11.96 & 4.73 & 85.02 & 0.13 & 2.22 & 0.25 & 0.42 \\
\hline & C-2-B & 82.80 & 12.23 & 4.97 & 83.96 & 0.24 & 2.76 & 0.34 & 0.47 \\
\hline & CC-B & 60.51 & 10.54 & 28.95 & 81.82 & 1.69 & 4.52 & 0.81 & 0.62 \\
\hline \multirow{4}{*}{ After acid treatment } & RD-A & 91.46 & 4.01 & 4.53 & 92.59 & 0.11 & 2.80 & 0.17 & 0.32 \\
\hline & C-1-A & 91.37 & 3.83 & 4.80 & 92.76 & 0.17 & 2.58 & 0.20 & 0.46 \\
\hline & C-2-A & 90.15 & 4.84 & 5.01 & 91.32 & 0.28 & 2.87 & 0.31 & 0.38 \\
\hline & CC-A & 84.39 & 3.27 & 12.34 & 87.67 & 1.45 & 6.36 & 0.73 & 0.52 \\
\hline
\end{tabular}

RD-B, C-1-B, C-2-B and CC-B are recycling dust, coke-1, coke-2 and coal char before acid treatment; RD-A, C-1-A, C-2-A and CC-A are recycling dust, coke-1, coke-2 and coal char after acid treatment; FC: fixed carbon; A: ash; $\mathrm{V}$ : volatile matter; d: dry basis; ${ }^{a}$ calculated by difference.

\subsection{Combustion Tests}

Thermogravimetric analysis was carried out using a WCT-2 differential thermal balance. A $5 \mathrm{mg}$ sample was placed in the alumina crucible and heated from room temperature to $1273 \mathrm{~K}$ under an oxygen atmosphere at heating rates of 5,10 and $20 \mathrm{~K} / \mathrm{min}$, respectively. The small amount of sample and slow heating rates were used to avoid heat transfer limitations and minimize the mass transfer effects. The gas flow rate was controlled by a mass flow meter at $100 \mathrm{~mL} / \mathrm{min}$ to remove the gaseous product in the combustion process. Fractional conversion $(X)$ during combustion process was calculated using the following equation:

$$
X=\Delta V / \Delta V^{*}
$$

where $V$ is percent of combustible matter at time $t ; V^{*}$ is the total content of combustible matter in the carbonaceous materials; $\Delta V$ is the mass loss at time $t ; \Delta V^{*}$ is the total mass loss.

\subsection{Characterization of Samples Combustion}

Researchers have come up with different kinds of characteristic combustion parameters to analyze combustion processes quantitatively $[18,19]$. Characteristic combustion parameters including initial combustion temperature $\left(T_{\mathrm{i}}\right)$, burnout temperature $\left(T_{\mathrm{b}}\right)$, maximum conversion rate $(\mathrm{d} X / \mathrm{d} t)_{\max }$ and average conversion rate $(\mathrm{dX} / \mathrm{d} t)_{\text {mean }}$ were thus used to evaluate the combustion process in the present study. Maximum conversion rate $1(\mathrm{~d} X / \mathrm{d} t)_{\max 1}$ and Maximum conversion rate $2(\mathrm{~d} X / \mathrm{d} t)_{\max 1}$ are the conversion rate values corresponding to the two peaks for recycling dust, respectively.

Combustibility of RD, C-1, C-2 and CC are characterized by the comprehensive combustive characteristic index $(S)[19]$ in the following equation:

$$
S=\frac{(\mathrm{d} X / \mathrm{d} t)_{\max } \cdot(\mathrm{d} X / \mathrm{d} t)_{\text {mean }}}{T_{\mathrm{i}}^{2} \cdot T_{\mathrm{b}}}
$$

where $(\mathrm{dX} / \mathrm{d} t)_{\max }$ is the maximum conversion rate $(\mathrm{mg} / \mathrm{min}) ;(\mathrm{dX} / \mathrm{d} t)_{\text {mean }}$ represents the mean value of the conversion rate $(\mathrm{mg} / \mathrm{min})$. 


\section{Kinetic Model}

Fractional conversion curves of all the samples were obtained using thermogravimetric analysis in the temperature programming progress, and the activation energy varied as the fractional conversion changed.

The distributed activation energy model (DAEM), originally developed by Vand [20], was improved by Pitt [21], Anthony [22] and Miura [23]. It is used to calculate the kinetic parameters during pyrolysis or combustion processes of biomass and coal and so on. Not only the average activation energy but also the variation trends during combustion processes can be obtained using this model. It assumes that a number of parallel and irreversible first order reactions that have different kinetic parameters occur simultaneously. The combustion of the experimental samples can be described using Equation (3) [24]:

$$
V / V^{*}=1-\int_{0}^{\infty} \exp \left(-\mathrm{k}_{0} \int_{0}^{t} e^{-E / R T} \mathrm{~d} t\right) f(E) \mathrm{d} E
$$

where $f(E)$ is distribution curve of activation energy; $k_{0}$ is the frequency factor corresponding to activation energy, $\mathrm{s}^{-1} ; E$ is the activation energy, $\mathrm{kJ} / \mathrm{mol} ; R$ is gas constant, $8.314 \mathrm{~J} /(\mathrm{mol} \cdot \mathrm{K})$; and $T$ is the absolute temperature, $\mathrm{K}$.

The temperature $(T)$ during a combustion reaction is controlled by the constant heating rate $\beta$ according to Equation (4):

$$
T=T_{0}+\beta t
$$

Equation (3) can be rewritten as Equation (5) by combining Equations (3) and (4):

$$
1-V / V^{*}=\int_{0}^{\infty} \Phi(E, T) f(E) \mathrm{d} E
$$

where $\Phi(E, T)=\exp \left(\frac{-k_{0}}{\beta} \int_{0}^{T} e^{-E / R T} \mathrm{~d} T\right)$, and it changes profoundly with the activation energy at a given temperature.

The activation energy of combustion reaction is treated approximately by a step function, and the treatment approximates that a reaction with activation energy occurs at a specified temperature and heating rate. The approximation is given mathematically in Equation (6):

$$
\mathrm{d} V / \mathrm{d} t=\mathrm{d}(\Delta V) / \mathrm{d} t=k_{0} e^{-E / R T}\left(\Delta V^{*}-\Delta V\right)
$$

By integrating and applying natural logarithms, Equation (6) can be written as Equation (7):

$$
\ln \left(\frac{\beta}{T^{2}}\right)=\ln \left(\frac{k_{0} R}{E}\right)-\ln (-\ln (1-X))-\frac{E}{R T}
$$

As shown in Equation (7), the activation energy and frequency factor are determined from the slope and intercept of plots of $\ln \left(\frac{\beta}{T^{2}}\right)$ versus $\frac{1}{T}$ at a given fractional conversion at different heating rates.

\section{Results and Discussion}

\subsection{Petrographic Analysis}

Petrographic analysis was used to distinguish unconsumed coal from unconsumed coke fines according to differential reflectance [13,15]. Petrographic micrographs with a magnification of $480 \times$ are shown in Figures 1 and 2. The results show that carbon in the RD mainly originates from unconsumed fine coke produced in the moving bed or hearth and unconsumed pulverized coal burnt in the dome. The microstructure of the unconsumed pulverized coal was found to be completely unconsumed coal (CUC), deformed coal (DC) and residue coal (RC) as shown in Figure 1. However, the microstructure of unconsumed fine coke (Figure 2) had several origins: granule inlay structure (GIS), flowing structure (FS), macro some (MS), block structure (BS), hemophilic silk carbon (HSC) and residue coke (RC). 

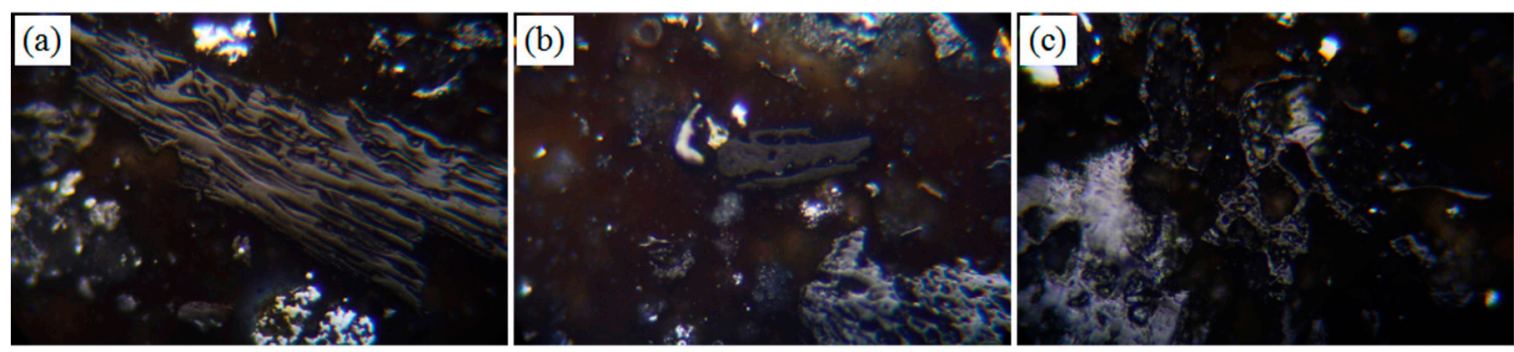

Figure 1. Microstructure of unconsumed pulverized coal in recycling dust: (a) completely unconsumed coal (CUC); (b) deformed coal (DC); and (c) residue coal (RC).
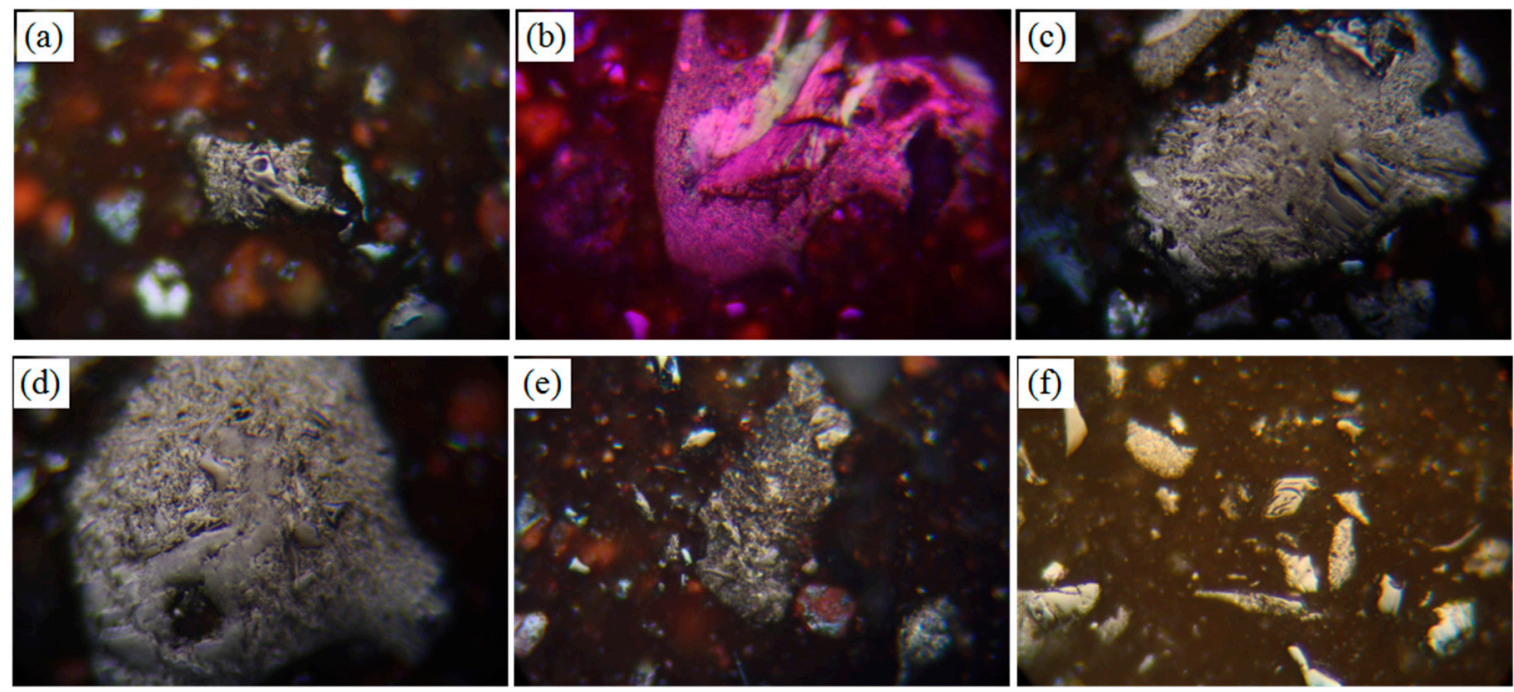

Figure 2. Microstructure of unconsumed fine coke in recycling dust: (a-c) granule inlay structure (GIS); (d) macro some (MS); (e) residue coke (RC); and (f) block structure (BS).

The results of percentage of microstructure area ratio of different parts in the RD are shown in Table 2. The data indicates that the carbonaceous materials include unconsumed fine coke and pulverized coal. The main structure types of unconsumed fine coke are granule inlay structures and residual coke, while completely unconsumed coal is the main structure type of unconsumed coal. According to the method proposed by Wu et al. [17], the mass fraction of unconsumed fine coke and pulverized coal in the RD was calculated, and the weight percentage of unconsumed fine coke and pulverized coal are $19.34 \%$ and $3.16 \%$, respectively.

Table 2. Percentage of micro structure area ratio of different parts in recycling dust $/ \%$.

\begin{tabular}{|c|c|c|c|c|c|c|c|c|c|}
\hline \multicolumn{4}{|c|}{ Unconsumed Fine Coke } & \multicolumn{3}{|c|}{ Unconsumed Coal } & \multicolumn{3}{|c|}{ Oxides } \\
\hline BS & FS & GIS & RC & CUC & $\mathrm{DC}$ & $\mathrm{RC}$ & slag & FS & others \\
\hline 1.90 & 1.27 & 18.03 & 9.18 & 6.23 & 1.02 & 0.98 & 33.23 & 23.10 & 5.06 \\
\hline
\end{tabular}

\subsection{Morphology of Carbonaceous Material of Samples}

The micromorphology of carbon in the RD, C-1, C-2 and CC was characterized using a SEM, and the results are shown in Figure 3.

Particles with both irregular and sharp edges are found in the RD under a magnification of $1000 \times$, in addition, ablative structures of incompletely reacted carbon are observed as well. The micromorphology of CC is characterized by solid particles with irregular edges and small pores, and a small amount of CC displays a smooth surface. Samples C-1 and C-2 are observed to have 
different morphology. Sample C-1 tends to show irregular edges and a rough surface, while C-2 shows sharp edges and a smooth surface. The different morphology of carbon in the RD indicates the complex origin of the carbon, which agrees with the petrographic analysis results.
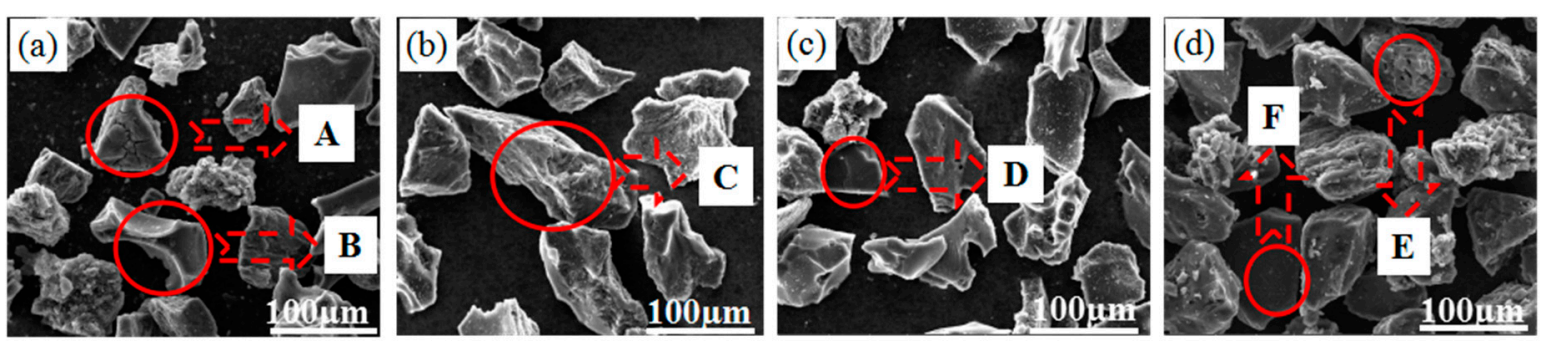

Figure 3. Morphology of carbonaceous materials in the recycling dust, coal char (CC) and coke: (a) RD; (b) C-1; (c) C-2; and (d) CC. A: ablative structure; B: irregular and sharp edge; C: irregular edge and rough surface; D: sharp edge and smooth surface; E: small pores; and F: irregular edge and smooth surface.

\subsection{Micro Crystalline Structure of Carbonaceous Material of Samples}

Although the micromorphology of samples could be obtained by SEM analysis, the structural parameters, which are of importance to explain difference of combustion profiles, could not be calculated. XRD is a well-established technique to determine the microcrystalline structural parameters of carbonaceous materials with good reliability [25-27]. The proportion of crystalline carbon and amorphous carbon indicates the degree of ordering of the carbon, which can be investigated by the average stack height $(L c)$. The average stacking height of carbon crystallites of carbonaceous material in this work is calculated using Scherrer's equation:

$$
L 002=\frac{0.89 \cdot \lambda}{\beta \cos \theta}
$$

where $\lambda$ is the wavelength of the X-ray source $(\mathrm{Cu} \mathrm{K} \alpha=0.154060 \mathrm{~nm}), \beta$ is the full width at half-maximum intensity ( $F W H M$ ) of the 002 reflection peak, and $\theta$ is the 002 carbon peak position. The diffraction pattern of acid treated recycling dust and other samples are shown in Figure 4.

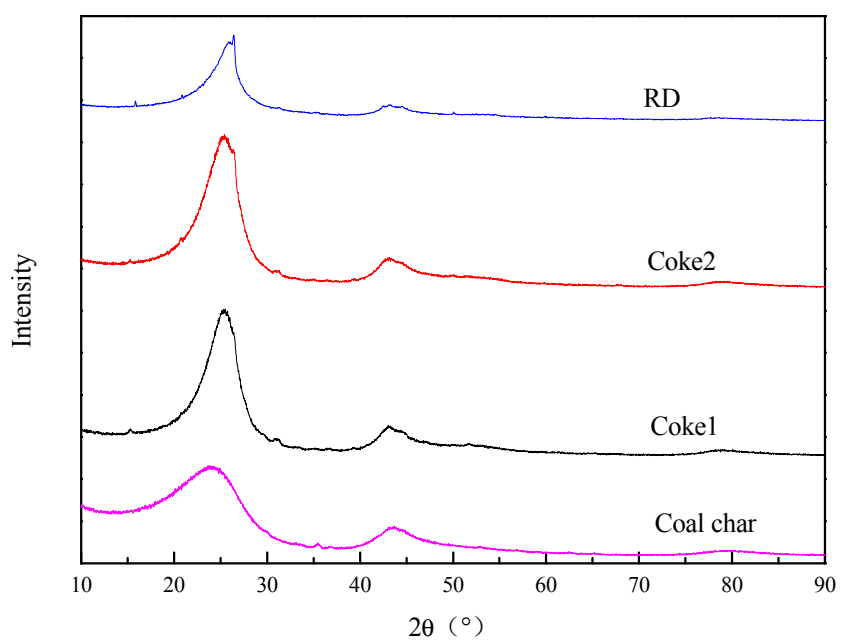

Figure 4. X-ray diffraction (XRD) spectra of RD, C-1, C-2 and CC.

All spectra display a clear (002) peak at about $25^{\circ}$ of $2 \theta$, and the 002 diffraction peak of CC presents a broad hump due to its turbostratic structure between graphite and an amorphous structure [28]. 
The 002 peaks of cokes and carbon in the recycling dust are sharper and narrower compared with CC, and the positions are found to shift to larger $2 \theta$ values, indicating that the microcrystalline structures of the carbonaceous materials tend to be more ordered. Meanwhile, average stacking height structural parameter $L c$ is calculated according to the XRD spectra and presented in Table 3.

As shown in Table 3, the smallest FWHM and largest $2 \theta$ value results in the largest average stacking height $L c$ of carbon in the $R D$, indicating that the carbon in the RD tends to be more ordered than that of C-1, C-2 and CC. Temperature is known to have a significant influence on the degree of graphitization of carbon, and a high temperature region of more than $3000 \mathrm{~K}$ can be formed in front of the dust burner due to the combustion of recycling dust [8]. The RD samples go through the high temperature zone resulting in aromatic carbon lamellas that were stacked higher in the spatial arrangement, and the graphitic structure of the recycling dust is more ordered than that of coal and coke.

Table 3. Average stacking height $L c$ of samples according to XRD spectra.

\begin{tabular}{cccc}
\hline Samples & $\mathbf{2 \theta} \mathbf{( 0 0 2 )}$ & FWHM (002) & Lc \\
\hline RD & 26.28 & 3.51 & 2.30 \\
C-1 & 25.60 & 3.53 & 2.28 \\
C-2 & 25.92 & 4.95 & 1.63 \\
CC & 24.84 & 6.94 & 1.16 \\
\hline
\end{tabular}

\subsection{Thermogravimetric Analysis}

Fractional conversion curves and conversion rate curves of the RD, C-1, C-2 and CC during combustion process are recorded in time by the computer, and the results are shown in Figure 5.
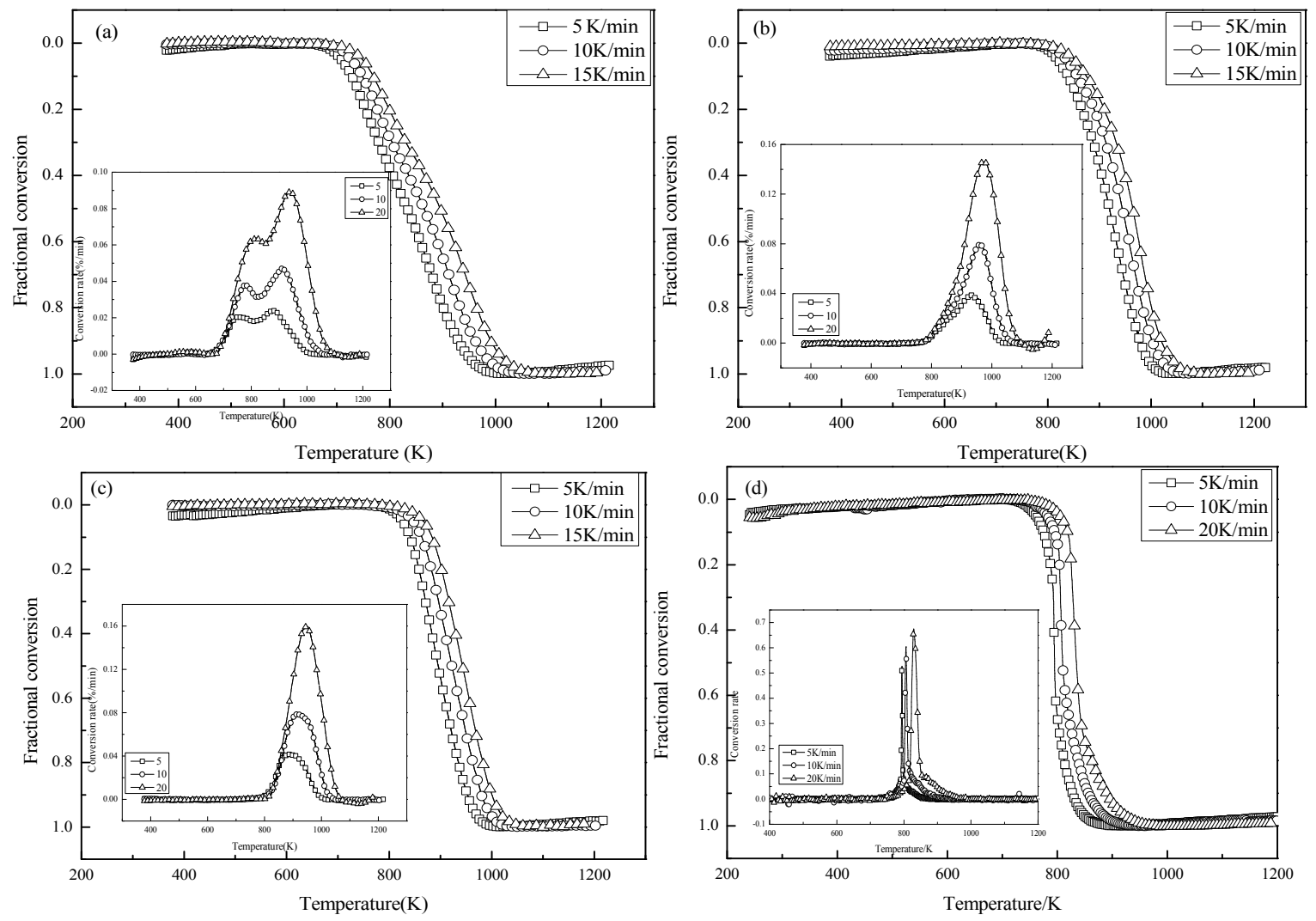

Figure 5. Fractional conversion curves and conversion rate curves of samples: (a) RD; (b) C-1; (c) C-2; and (d) CC. 
The combustion of RD samples is different from that of C-1, C-2 and CC, as shown in Figure 5. There are two characteristic peaks at approximately $810 \mathrm{~K}$ and $940 \mathrm{~K}$ in the conversion rate curves of the RD sample, indicating that different carbonaceous materials burn in order during the combustion process. The carbonaceous materials in the recycling dust mainly consists of unconsumed CC and unconsumed coke fines, according to the petrographic analysis results. Therefore, the combustion process of the RD sample can be divided into four stages including combustion of volatile matter, CC, unconsumed coke fine and burnout process.

The combustion processes of C-1, C-2 and CC are similar to each other, and can be divided into three stages, including combustion of volatile matter, residue char and burnout process. The combustion temperature range of CC is the smallest, indicating a drastic weight loss reaction occurs due to the higher volatile matter content and smaller $L_{C}$ value. The carbonaceous material in the RD sample consists of unconsumed coal and coke fines according to the petrographic analysis. The specific surface area of unconsumed CC with more pores and smaller particle size is higher than that of the unconsumed coke fines. Therefore, the unconsumed pulverized coal burns first and unconsumed coke fines burns afterwards, and the combustion profiles show differences with the CC and coke samples indicating that the combustion mechanism of the recycling dust is different from that of C-1, C-2 and CC.

The characteristic combustion parameters of different samples are shown in Table 4. $T_{\mathrm{i}}$ of the $\mathrm{RD}$ is $699 \mathrm{~K}$ to $732 \mathrm{~K}$ at different heating rates and $T_{\mathrm{b}}$ are $986 \mathrm{~K}$ to $1034 \mathrm{~K}$ indicating a larger reaction temperature range. The ignition temperatures of $\mathrm{C}-1$ at the three heating rates are smaller than that of $\mathrm{C}-2$, and $T_{\mathrm{b}}$ of $\mathrm{C}-1$ is $1006 \mathrm{~K}$ to $1057 \mathrm{~K}$, which is a little higher than $\mathrm{C}-2$. The reaction temperature range of $\mathrm{C}-1$ is obviously narrower than that of $\mathrm{C}-2$, indicating that combustion reaction of $\mathrm{C}-1$ is more drastic due to less ordered micro crystalline structure. $T_{\mathrm{b}}$ of $C \mathrm{C}$ is much smaller than that of $\mathrm{C}-1, \mathrm{C}-2$ and the $\mathrm{RD}$, resulting smallest temperature range. The relatively narrow reaction temperature range and high conversion rate of $\mathrm{CC}$, indicating a severe combustion reaction under enriched oxygen atmosphere due to higher volatile matter content and smaller carbon stack height.

Table 4. Characteristic temperatures and comprehensive combustive characteristic index $S$.

\begin{tabular}{|c|c|c|c|c|c|c|c|c|c|}
\hline Sample & $\beta /\left({ }^{\circ} \mathrm{C} / \mathrm{min}\right)$ & $T_{\mathrm{i}} / \mathrm{K}$ & $T_{\mathrm{b} 1} / \mathrm{K}$ & $T_{\mathrm{b} 2} / \mathrm{K}$ & $\begin{array}{c}(\mathrm{d} G / \mathrm{d} t)_{\max 1} \\
(\mathrm{mg} / \mathrm{min})\end{array}$ & $\begin{array}{c}(\mathrm{d} G / \mathrm{d} t)_{\max 2} \\
(\mathrm{mg} / \mathrm{min})\end{array}$ & $\begin{array}{c}(\mathrm{d} G / \mathrm{d} t)_{\text {mean } 1} \\
(\mathrm{mg} / \mathrm{min})\end{array}$ & $\begin{array}{c}(\mathrm{d} G / \mathrm{d} t)_{\text {mean2 }} \\
(\mathrm{mg} / \mathrm{min})\end{array}$ & $\begin{array}{c}S \times 10^{-13} \\
\left(\mathrm{mg}^{2} /\left(\min ^{2} \cdot{ }^{\circ} \mathrm{C}\right)\right)\end{array}$ \\
\hline \multirow{3}{*}{$\mathrm{RD}$} & 5 & 699 & 808 & 986 & 0.018 & 0.025 & 0.004 & 0.008 & 2.66 \\
\hline & 10 & 716 & 819 & 1002 & 0.032 & 0.053 & 0.006 & 0.018 & 11.39 \\
\hline & 20 & 732 & 860 & 1034 & 0.065 & 0.093 & 0.015 & 0.038 & 37.29 \\
\hline \multirow{3}{*}{ C-1 } & 5 & 802 & - & 1006 & 0.037 & - & 0.006 & - & 3.43 \\
\hline & 10 & 815 & - & 1034 & 0.079 & - & 0.011 & - & 12.65 \\
\hline & 20 & 828 & - & 1057 & 0.146 & - & 0.024 & - & 48.35 \\
\hline \multirow{3}{*}{$C-2$} & 5 & 809 & - & 978 & 0.042 & - & 0.006 & - & 3.94 \\
\hline & 10 & 824 & - & 1007 & 0.079 & - & 0.012 & - & 13.87 \\
\hline & 20 & 841 & - & 1029 & 0.159 & - & 0.024 & - & 52.43 \\
\hline \multirow{3}{*}{ CC } & 5 & 746 & - & 866 & 0.517 & - & 0.006 & - & 64.36 \\
\hline & 10 & 763 & - & 898 & 0.600 & - & 0.012 & - & 137.72 \\
\hline & 20 & 787 & - & 940 & 0.659 & - & 0.020 & - & 226.38 \\
\hline
\end{tabular}

Comprehensive combustive characteristic indexes $(S)$ of all the samples were calculated according to Equation (1). The results show that comprehensive combustion characteristic index (S) of CC is one order of magnitude higher than that of the RD as well as C-1, and C-2. Because the volatile matter content of CC is about three times higher than that of the other samples, and the amorphous carbon ratio in CC is higher, so CC shows better combustion reactivity. The $S$ of the RD is smallest among the samples, mainly due to its more ordered microcrystalline structure, which results in less active components. Combustibility of carbon is connected with degree of graphitization determined by ratio of aromatic and amorphous carbon, and larger $L_{C}$ value of RD indicates a higher degree of graphitization. 


\subsection{Kinetic Analysis}

The conversion from 0.02 to 0.98 was selected to calculate the kinetic parameters with different fractional conversions at different heating rates. Activation energy and frequency factor corresponding to the fractional conversion are calculated by linear fitting, and the plots are shown in Figure 6.

According to the plots, the results of activation energy and frequency factor for various carbonaceous material are obtained. The average activation energy of combustion process of the $\mathrm{RD}, \mathrm{C}-1, \mathrm{C}-2$ and CC are $191.84 \mathrm{~kJ} / \mathrm{mol}, 243.60 \mathrm{~kJ} / \mathrm{mol}, 217.77 \mathrm{~kJ} / \mathrm{mol}$ and $128.31 \mathrm{~kJ} / \mathrm{mol}$, and the corresponding frequency factors are observed to be in the order of $10^{8}, 10^{13}, 10^{10}$ and $10^{4} \mathrm{~s}^{-1}$, respectively. The activation energy of CC ranges from $95.15 \mathrm{~kJ} / \mathrm{mol}$ to $169.99 \mathrm{~kJ} / \mathrm{mol}$ during combustion process with oxygen content ranging from $21 \%$ to $100 \%$ according to Zhang et al. [29] using Flynn-Wall-Ozawa method. Activation energies reported in literature are lower than the results in this study. This could be attributed to the pyrolysis treatment used for CC in this study, which is treated at $1473 \mathrm{~K}$ for $30 \mathrm{~min}$, and the more ordered carbon structures of C-1, C-2 and the RD.
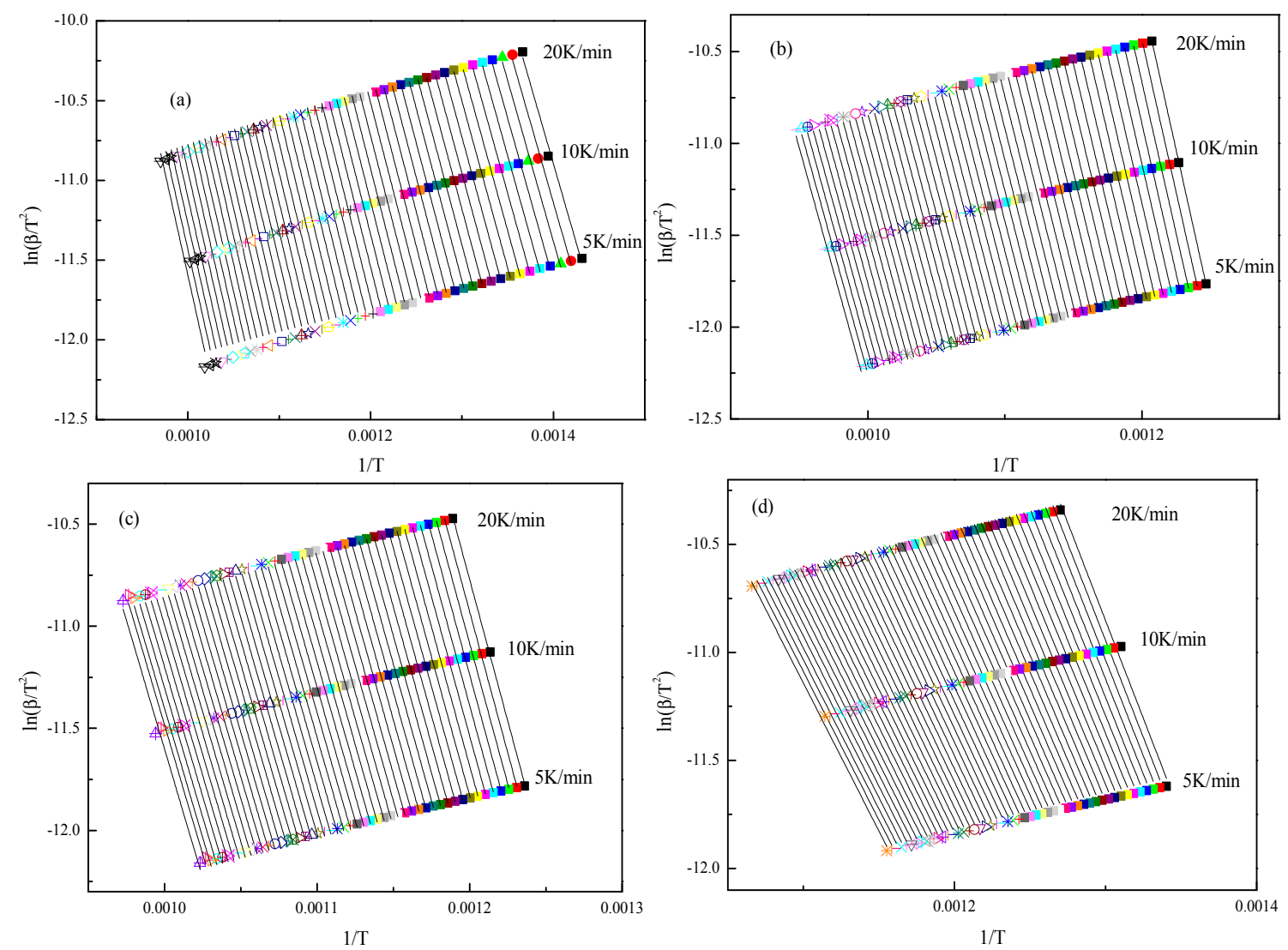

Figure 6. Plots of $\ln \left(\frac{\beta}{T^{2}}\right)$ vs. $\frac{1}{T}$ at a given fractional conversion at different heating rates: (a) RD; (b) C-1; (c) C-2; and (d) CC.

It can be inferred that the average activation energy of the RD is higher than that of $\mathrm{CC}$ and lower than that of C-1 and C-2, and the corresponding frequency factor is much smaller than that of $C-1$ and C-2. Activation energy expresses the energy needed for activation of molecules, and the frequency factor stands for the effective collision chances for a molecule. Although the activation energy of the $\mathrm{RD}$ is smaller than that of $\mathrm{C}-1$ and $\mathrm{C}-2$, the frequency factor is much smaller, which is the main reason for the smaller comprehensive combustion characteristic index of RD compared to that of $\mathrm{C}-1$ and $\mathrm{C}-2$. The activation energy and frequency factor of CC are smaller than that of $\mathrm{C}-1$ and $\mathrm{C}-2$, and the comprehensive combustion characteristic index is larger. On the one hand, the volatile matter content of $\mathrm{CC}$ is higher than that of the $\mathrm{RD}$, which benefits the combustion reactivity. On the other hand, 
the RD includes different carbonaceous materials, which influence the combustion reactions together during combustion process. The combustion mechanism of the RD is different from that of CC, C-1 and $\mathrm{C}-2$, and there does not exist an exactly corresponding relationship between activation energy and comprehensive combustion characteristic index for the RD.

In addition to the average kinetic parameters, the distributed activation energy curves were shown in Figure 7. Each reaction step of the conversion has a corresponding activation energy throughout the combustion process. The activation energy of the RD increases with increasing fractional conversion from 0.02 to 0.98 , which is different from that of C-1, C-2 and CC. The activation energy of other samples tends to decrease with increasing fractional conversion, and there exists a transitory stage for $\mathrm{CC}$ when fractional conversion increases from 0.4 to 0.75 . The various distributed activation energy curves indicate different mechanisms for carbonaceous materials from various origins.

At low temperature ranges, the combustion reaction of CC is controlled mainly by chemical reactions, while diffusion tends to control the combustion reaction with increasing temperature according to Wang et al. [30]. The activation energy in the chemical reaction controlled process is higher, and it tends to decrease in the diffusion controlling process which appears at higher temperatures.
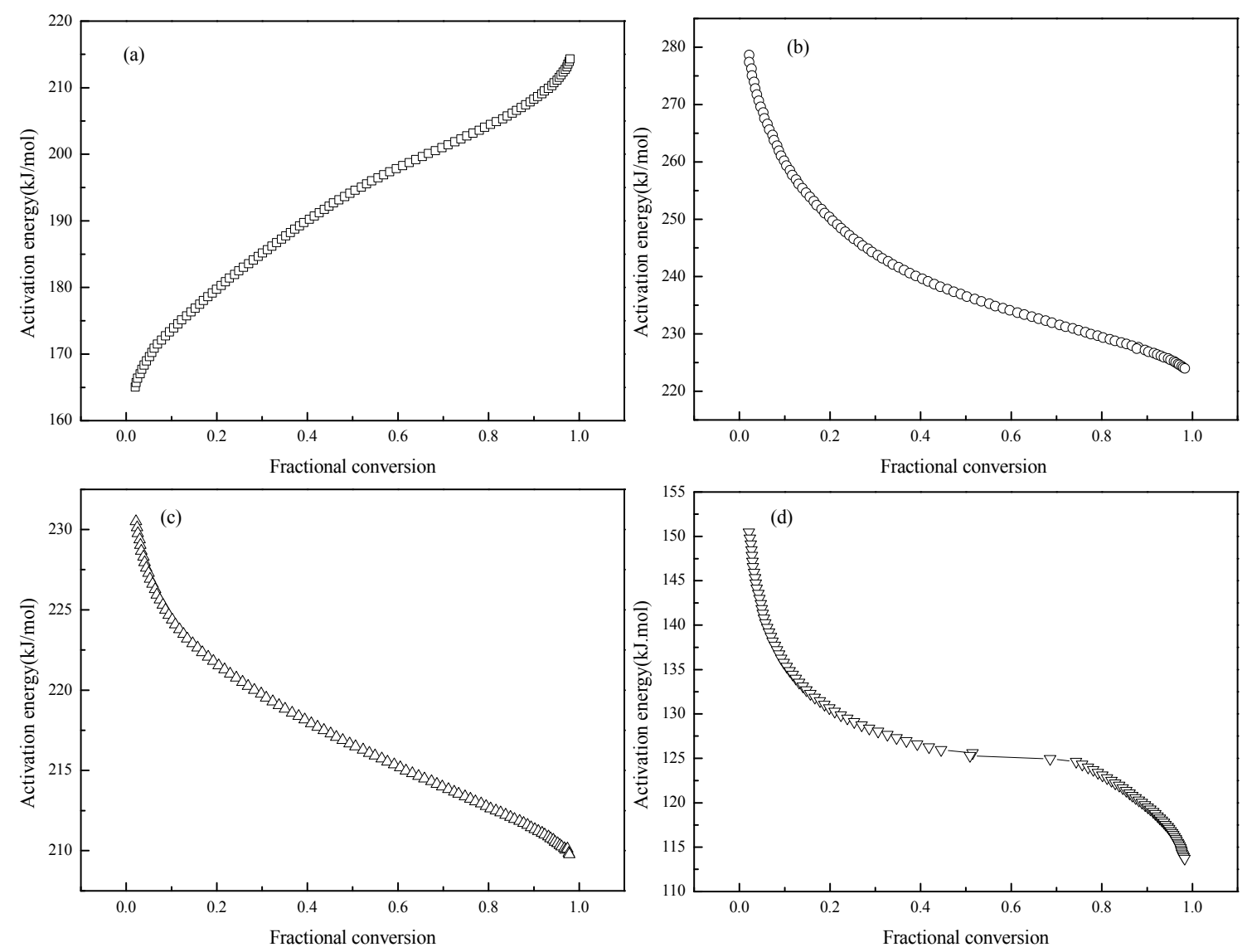

Figure 7. Distributed activation energy curves of samples: (a) RD; (b) C-1; (c) C-2; and (d) CC.

The combustion of CC, C-1 and C-2 are typical reactions controlled by chemical reactions in the low temperature range and by diffusion at a higher temperature range according to unreacted core model [31]. Therefore, the activation energy of CC, C-1 and C-2 tends to decrease with increasing fractional conversion. However, RD samples consist of complex carbonaceous materials, which burn in order but not completely independently, and there exists an interaction effect between carbons of different origin. Carbonaceous material with high reactivity in the RD burns first, followed by carbon with low reactivity. Combustible components decrease with increasing fractional conversion, and the 
reaction difficulty tends to increase gradually, which is the main reason that the activation energy of $\mathrm{RD}$ increases with conversion increasing.

\section{Conclusions}

The carbonaceous material in the recycling dust originates from unconsumed CC and coke fines, and the mass ratios are about $3.16 \%$ and $19.34 \%$, respectively. The more ordered carbon structure of carbonaceous materials in the recycling dust results in poor combustion reactivity, which can be seen through the comprehensive combustion characteristic index results. The combustion mechanism of the recycling dust is different from that of C-1, C-2 and CC, and there are two characteristic peaks in the conversion rate curves of the recycling dust at different heating rates. The kinetic parameters are calculated using DAEM, and the average activation energy of the recycling dust is $191.84 \mathrm{~kJ} / \mathrm{mol}$ with a corresponding frequency factor on the order of $108 \mathrm{~s}^{-1}$. The activation energy of the recycling dust increases with increasing fractional conversion, however, the tendency for C-1, C-2 and CC is regularly the opposite. The different tendency indicates different combustion reaction mechanisms. Simulated calculation is one of the valid methods to provide design and optimization directions for complex reactors in recent years. The investigation of the combustion characteristics and mechanism of the recycling dust could provide theoretical support for determining the parameters to be used for simulated calculations of dust burners.

Acknowledgments: The present work was financially supported by National Natural Science Foundation of China (No. U1260202).

Author Contributions: Haiyang Wang and Guangwei Wang conceived and designed the study. Di Zhao, Jian Guo and Tengfei Song helped perform the experiments. Haiyang Wang wrote the paper. Guangwei Wang and Jianliang Zhang reviewed and edited the manuscript. All authors read and approved the manuscript.

Conflicts of Interest: The authors declare no conflict of interest.

\section{References}

1. Siuka, D.; BÖhm, C.; Wieder, K. COREX and FINEX technology process updates. In Proceedings of the Baosteel Biennial Academic Conference, Shanghai, China, 25-26 May 2006; pp. 8-16.

2. $\mathrm{Li}, \mathrm{W}$. The operature states and technical problems for COREX-3000. In Proceedings of the 3rd Baosteel Biennial Academic Conference, Shanghai, China, 26-28 September 2008; pp. 75-83.

3. Hao, S.L.; Xu, H.F.; Li, Z.Y.; Zhang, Q.; Lin, J.J. Study of the characteristics in shaft furnace of COREX-3000 process. In Proceedings of the Third Baosteel Biennial Academic Conference, Shanghai, China, 26-28 September 2008; pp. 102-107.

4. Wu, S.; Yang, S.; Xu, J.; Zhou, Q.; Guo, X.; Zhang, L. Study on thermodynamic and kinetic characteristics in COREX shaft furnace. In Proceedings of the 5th International Congress on the Science and Technology of Ironmaking, Shanghai, China, 20-22 October 2009; pp. 1275-1279.

5. Sun, J.; Wu, S.; Kou, M.; Shen, W.; Du, K. Influence of operation parameters on dome temperature of COREX melter gasifier. ISIJ Int. 2014, 54, 43-48. [CrossRef]

6. Liu, Q.H.; Wu, K.; Wang, H.Y.; Zhang, Z.C.; Shao, T.F.; Qu, J.J; Wang, C.M. Kinetic study of tar's separation from coals used in COREX. J. China Coal Soc. 2012, 37, 1749-1752.

7. Berger, K.; Weiss, C.; Kepplinger, W.L. CFD simulation of the carbon dust combustion in the COREX ${ }^{\circledR}$ melter gasifier. Steel Res. Int. 2008, 79, 579-586. [CrossRef]

8. Wu, S.; Du, K.; Zhang, Z.; Chang, F. Characterization of recycling dust and simulation of its combustion in freeboard of COREX melter gasifier. In Proceedings of the 6th China-Korea Joint Symposium on Advanced Steel Technology, Nanjing, China; 2014; pp. 1-9.

9. Du, K.; Wu, S.; Zhang, Z.; Chang, F.; Liu, X. Analysis on inherent characteristics and behavior of recycling dust in freeboard of COREX melter gasifier. ISIJ Int. 2014, 54, 2737-2745. [CrossRef]

10. Liu, X.; Chen, M.; Wei, Y. Assessment on oxygen enriched air co-combustion performance of biomass/bituminous coal. Renew. Energy 2016, 92, 428-436. [CrossRef]

11. Gong, X.; Guo, Z.; Wang, Z. Effect of coal characteristics on its combustion catalyzed by $\mathrm{CeO}_{2}$. J. Fuel Chem. Technol. 2010, 38, 29-34. 
12. Wang, K.; Guo, X.; Zhao, P.; Wang, F.; Zheng, C. High temperature capture of $\mathrm{CO}_{2}$ on lithium-based sorbents from rice husk ash. J. Hazard. Mater. 2011, 189, 301-307. [CrossRef] [PubMed]

13. Iwanage, Y. Investigation on Behavior of Unburnt Pulverized Coal in Blast Furnace. ISIJ Int. 1991, 31, 494-499. [CrossRef]

14. Yamagata, C.; Suyama, S.; Horisaka, S.Y.; Takatani, K.; Kajiwara, Y.; Komatsu, S.; Shibuta, H.; Aminaga, Y. Fundamental Study on Combustion of Pulverized Coal Injected into Coke Bed at High Rate. ISIJ Int. 1992, 32, 725-732. [CrossRef]

15. Yamaguchi, K.; Ueno, H.; Matsunaga, S.I.; Kakiuchi, K.; Amano, S. Test on High-Rate Pulverized Coal Injection Operation at Kimitsu No. 3 Blast Furnace. ISIJ Int. 1995, 35, 148-155. [CrossRef]

16. Ichida, M.; Nakayama, T.; Tamura, K.; Shiota, H.; Araki, K.; Sugisaki, Y. Behavior of Fines in the Blast Furnace. ISIJ Int. 1992, 32, 505-513. [CrossRef]

17. Wu, K.; Ding, R.; Han, Q.; Yang, S.; Wei, S.; Ni, B. Research on unconsumed fine coke pulverized coal of BF dust under different PCI rates in BF at Capital Steel CO. ISIJ Int. 2010, 50, 390-395. [CrossRef]

18. Wang, G.; Zhang, J.; Shao, J.; Ren, S. Characterization and model fitting kinetic analysis of coal/biomass co-combustion. Thermochim. Acta 2014, 591, 68-74. [CrossRef]

19. Wang, G.; Zhang, J.; Hou, X.; Shao, J.; Geng, W. Study on $\mathrm{CO}_{2}$ gasification properties and kinetics of biomass chars and anthracite char. Bioresour. Technol. 2015, 177, 66-73. [CrossRef] [PubMed]

20. Vand, V. A theory of the irreversible electrical resistance changes of metallic films evaporated in vacuum. Proc. Phys. Soc. 1943, 55, 222. [CrossRef]

21. Pitt, G.J. The kinetics of the evolution of volatile matter products from coal. Fuel 1962, 41, 267-274.

22. Anthony, D.B.; Howard, J.B.; Hottel, H.C. Rapid devolatilization of pulverized coal. In Proceedings of the 15th Symposium on Combustion, Tokyo, Japan, 25-31 August 1974; pp. 1303-1317.

23. Miura, K. A new and simple method to estimate $f(\mathrm{E})$ and $k_{0}(\mathrm{E})$ in the distributed activation energy model from three sets of experimental data. Energy Fuels 1995, 9, 302-307. [CrossRef]

24. Bhavanam, A.; Sastry, R.C. Kinetic study of solid waste pyrolysis using distributed activation energy model. Bioresour. Technol. 2015, 178, 126-131. [CrossRef] [PubMed]

25. Lu, L.; Sahajwalla, V.; Kong, C.; Harris, D. Quantitative X-ray diffraction analysis and its application to various coals. Carbon 2001, 9, 1821-1833. [CrossRef]

26. Gupta, S.; Sahajwalla, V.; Chaubal, P.; Youmans, T. Carbon structure of coke at high temperatures and its influence on coke fines in blast furnace dust. Metall. Mater. Trans. B 2005, 36, 385-394. [CrossRef]

27. Gupta, S.; Ye, Z.; Kanniala, R.; Kerkkonen, O.; Sahajwalla, V. Coke graphitization and degradation across the tuyere regions in a blast furnace. Fuel 2013, 113, 77-85. [CrossRef]

28. Manoj, B.; Kunjomana, A.G. Study of stacking structure of amorphous carbon by X-ray diffraction technique. Int. J. Electrochem. Sci. 2012, 7, 3127-3134.

29. Zhang, J.; Wang, G.; Xing, X. Study on the combustion characteristics and kinetics of pulverized coal in oxygen-enriched environments. J. Iron Steel Res. Int. 2013, 4, 9-14.

30. Wang, G.W.; Zhang, J.L.; Shao, J.G.; Hui, S.U.; Zuo, H.B. Thermogravimetric analysis of coal char combustion kinetics. J. Iron Steel Res. Int. 2014, 21, 897-904. [CrossRef]

31. Ochoa, J.; Cassanello, M.C.; Bonelli, P.R.; Cukierman, A.L. $\mathrm{CO}_{2}$ gasification of Argentinean coal char a kinetic characterization. Fuel Process. Technol. 2001, 74, 161-176. [CrossRef]

(c) 2017 by the authors; licensee MDPI, Basel, Switzerland. This article is an open access article distributed under the terms and conditions of the Creative Commons Attribution (CC BY) license (http:/ / creativecommons.org/licenses/by/4.0/). 